Sädhanā, Vol. 19, Part 5, October 1994, pp. 705-721. (C) Printed in India.

\title{
Interaction between a buoyancy-driven flow and an array of annular cavities
}

\author{
M MOLKI ${ }^{1}$ and M FAGHRI $^{2}$ \\ ${ }^{1}$ Department of Mechanical Engineering, Esfahan University of \\ Technology, Esfahan, Iran \\ ${ }^{2}$ Department of Mechanical Engineering and Applied Mechanics, \\ University of Rhode Island, Kingston, RI 02881, USA
}

\begin{abstract}
A numerical study is performed to investigate the interaction between a buoyancy-induced flow and an array of annular cavities. The buoyant flow is generated in a vertical annular enclosure with a centrallypositioned finned inner cylinder. Heat is generated within the inner cylinder, and it is convected through the inter-fin cavities and annular enclosure to the outside environment. The results indicate the presence of a twin recirculating bubble in each cavity. At higher Ra, the main flow enters the cavities and removes the recirculating flow. These observations are more pronounced at higher Pr. For more slender and deeper cavities, the recirculating bubbles closer to the finned wall collapse and split into two bubbles. The presence of cavities create a nearly uniform hightemperature zone adjacent to the finned wall. As the fin length is reduced and the cavities become more shallow, this zone shrinks and the main buoyancy-driven flow maintains a closer thermal communication with the finned wall.
\end{abstract}

Keywords. Heat transfer; cavity; buoyancy; annular.

\section{Introduction}

Buoyancy-driven flows in enclosures have been the subject of study for many years and the published literature on the subject is diverse and rich (Catton 1978; Ostrach 1982, 1988; Hoogendoorn 1986). A number of investigators have been interested in cavity-driven flow with the flow generated by the motion of the upper wall (Bozeman \& Dalton 1973; Ozawa 1975; Tuann \& Olson 1978; Benjamin \& Denny 1979; Ghia et al 1982; Schreiber \& Keller 1983; Iwatsu et al 1989, 1990, 1992) while others have studied the effect of thermally-induced buoyancy on the flow field.

Although the existing literature on square cavities is rich, the number of investigations concerned with annular cavities is fairly limited. The focus of the previous studies has been in two directions; one to gain better understanding of the flow field, and the other to explore the thermal behaviour of the problem. In fact, the coupling of the governing equations in thermally-driven flows links these objectives together. 
One of the pioneering works on natural convection in annular cavities was performed by De Vahl Davis \& Thomas (1969) who employed a numerical technique and reported flow and heat transfer results. In another effort, Thomas \& De Vahl Davis (1970) classified the flow into three regimes, namely conduction, transition, and boundary layer regimes, and presented correlations for each regime. Other related works are the experimental investigations of Collier et al (1970), who employed carbon dioxide at high pressures and temperatures, the analytical and experimental studies of Nagendra et al (1970), and the experimental work of Sheriff (1966).

Experiments on a vertical annulus where the inner cylinder is at constant heat flux and the outer cylinder at constant temperature are performed by Keyhani et al (1983). They used air and helium as working fluids and conducted their measurements at a fixed aspect and radius ratio. Bhushan et al (1983) continued the studies of Keyhani et al (1983) with the same experimental setup and performed experiments with air and helium at higher pressures. They arrived at new and more general correlations for conduction and boundary layer regimes which included the effect of aspect and radius ratio on heat transfer coefficient. However, the results are valid for the annuli with constant surface heat flux at the inner cylinder.

Experiments of Prasad \& Kulacki (1985) were performed at higher values of Rayleigh number and with the inner and outer surfaces maintained at constant temperature. They indicated that turbulence is initiated when the local Grashof number reaches $4 \times 10^{9}$. Other related studies are the experiments reported by Vijayan et al (1986) on two methods of reduction of buoyancy-driven flow in a vertical annulus open to hot fluid at the bottom, the numerical results of Lin $\&$ Nansteel (1987) for water at maximum density, the experimental work of Molki \& Shahsavan (1989) on a vertical annulus filled with atmospheric air and immersed in a water bath to provide a convective environment on the outside surface of the annulus, and the numerical results reported by Farouk et al (1990).

Despite the existence of the above references on buoyancy-driven flows in annular cavities, the interaction between annular cavities appears to be scarce. The present investigation is concerned with the flow and temperature fields which result from the interaction between a byouancy-induced flow and an array of annular cavities. The flow is induced by thermal gradient in an annular enclosure where a finned inner cylinder is situated at its centre. The interfin spacings form the array of open cavities which are exposed to the buoyant flow.

This type of interaction arises in many engineering devices. For instance, the finned surfaces form an array of open cavities whose thermal-hydraulic performance depends on the nature of its interaction with the neighbouring fluid. In particular, the inner cylinder of the present geometry may be considered to be a heat-generating electronic component which is shrouded in a cylindrical container to protect it against the harsh environment. This aspect of the buoyancy-driven flow appears to be new and has not attracted the attention of other investigators.

\section{Description, formulation, and methodology}

\subsection{Statement of the problem}

The simplified view of the problem is shown in figure 1 . A solid cylinder of radius $R_{i}$ and height $H$ is located in a larger hollow cylinder of radius $R_{0}$ to form the annular enclosure. In this figure only the enclosure and the finned surface of the inner cylinder 
CAVITIES

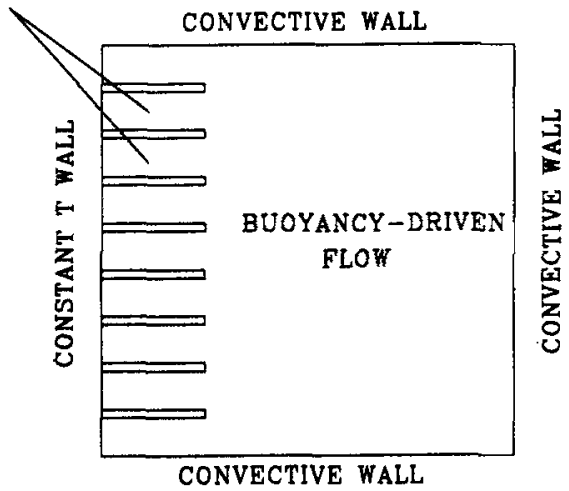

Figure 1. Geometry of the problem; the finned surface at the left is the surface of the inner cylinder.

are shown. The fins are equally spaced to form the array of annular cavities. Heat is generated within the inner cylinder at the uniform rate $s$ per unit volume. The outer boundaries of the enclosure are exposed to a convective environment at $T_{\infty}$ and $h$. With this arrangement, the thermal energy generated in the finned wall is transferred to the outside environment by natural convection through the annular fluid. The circumferential fins form the array of open cavities and interact with the buoyancy-driven main flow in the annulus. It should be noted that the solutions are based on the large value of thermal conductivity for the inner wall so that the thermal boundary condition on the finned wall may be considered to be uniform temperature.

\subsection{Governing differential equations}

The governing equations are conservation of mass, momentum, and energy for the fluid, and the energy equation for the inner finned solid. All the thermophysical properties are assumed to be constant, except for the density in the buoyancy term where Boussinesq approximation is used. The dimensionless governing differential equations are,

$$
\begin{aligned}
& \frac{1}{R} \frac{\partial}{\partial R}(R V) \frac{\partial U}{\partial X}=0, \\
& U \frac{\partial U}{\partial X}+V \frac{\partial U}{\partial R}=-\frac{\partial P}{\partial X}+\left[\frac{1}{R} \frac{\partial}{\partial R}\left(R \frac{\partial U}{\partial R}\right)+\frac{\partial^{2} U}{\partial X^{2}}\right]+\frac{R a}{\operatorname{Pr}} T \\
& U \frac{\partial V}{\partial X}+V \frac{\partial V}{\partial R}=-\frac{\partial P}{\partial R}+\left[\frac{1}{R} \frac{\partial}{\partial R}\left(R \frac{\partial V}{\partial R}\right)+\frac{\partial^{2} V}{\partial X^{2}}\right]-\frac{V}{R^{2}} \\
& U \frac{\partial T}{\partial X}+V \frac{\partial T}{\partial R}=\frac{1}{\operatorname{Pr}}\left[\frac{1}{R} \frac{\partial}{\partial R}\left(R \frac{\partial T}{\partial R}\right)+\frac{\partial^{2} T}{\partial X^{2}}\right]+\frac{K S}{\operatorname{Pr}} \\
& \frac{1}{R} \frac{\partial}{\partial R}\left(R \frac{\partial T}{\partial R}\right)+\frac{\partial^{2} T}{\partial X^{2}}+S=0 .
\end{aligned}
$$

In these equations, the dimensionless parameters are defined as,

$$
X=X / L, \quad R=r / L,
$$




$$
\begin{aligned}
U & =u /(v / L), \quad V=v /(v / L), \quad T=t / t_{\infty}, \\
P & =p^{*} /\left[\rho(v / L)^{2}\right], \quad p^{*}=p+\rho_{r} g\left(1+\beta T_{r}\right)(H-x), \\
\operatorname{Ra} & =g \beta L^{3} T_{\infty} /(v \alpha), \quad \operatorname{Pr}=(v / \alpha), \quad K=\left(k_{s} / k_{f}\right), \quad S=\left(L^{2} / k_{s} T_{\infty}\right) s .
\end{aligned}
$$

To complete the formulation of the problem, the boundary conditions are specified as: (1) on all solid boundaries, $U=V=0$; (2) at the centreline of the inner cylinder (not shown in figure 1),

$$
\partial T / \partial R=0
$$

(3) at the top and bottom walls,

$$
\begin{array}{ll}
\text { solid } & \pm \partial T / \partial X=\mathrm{Bi}(T-1), \\
\text { fluid } & \mp \partial T / \partial X=\mathrm{Nu}_{\infty}(T-1),
\end{array}
$$

where the negative and positive signs apply respectively to the top and bottom walls;

(4) at the outer cylindrical wall,

$$
-\partial T / \partial R=\mathrm{Nu}_{\infty}(T-1)
$$

(5) at the solid-fluid interface, $T_{s}=T_{f}$ and

$$
K(\partial T / \partial N)_{s}=(\partial T / \partial N)_{f}
$$

In these equations, $\mathrm{Bi}=h L / k_{s}, \mathrm{Nu}_{\infty}=h L / k_{f}$, and $N=n / L$, where $n$ is a space coordinate normal to the interface. Moreover, the geometric parameters which identify the annulus and the fins are, radius of the outer cylinder $R_{o}=r_{o} / L$, annulus height $H=h / L$, fin length $L_{f}=l_{f} / L$, fin thickness $T_{f}=t_{f} / L$, and the number of fins $n_{f}$. It is noteworthy that the radius of the inner cylinder $R_{i}=r_{i} / L$, is related to $R_{o}$ through $R_{i}=R_{o}-1$. Once one of the two radii is known, the other is readily found. In this connection, the ratio of the outer radius to the inner radius, $r_{o} / r_{i}=R_{o} / R_{i}$, has emerged as a major geometric parameter.

Examination of (1)-(9) and the boundary conditions indicate that the dependent variables, namely $U, V, P$, and $T$, are functions of $X, R, \operatorname{Ra}, \operatorname{Pr}, K, \mathrm{Nu}_{\infty}, S, R_{o} / R_{i}$, $H, L_{f}, T_{f}$, and $n_{f}$. In this study, Ra ranged from 1000 to 1000,000 , Pr from 0.7 to $1000, L_{f}$ from $1 / 64$ to $1 / 2, T_{f}$ from 0.009 to 0.087 , and $n_{f}$ from 0 to 16 . To save on the computation time, the remaining variables were fixed at values $K=2800$, $\mathrm{Nu}_{\infty}=20, S=0.04, R_{o} / R_{i}=2$, and $H=1$. This value of $K$ corresponds to a practical situation where the inner cylinder is made of iron and the cavity fluid is air. The values for $\mathrm{Nu}_{\infty}$ and $S$ are other realistic values close to those encountered in the studies of Molki \& Shahsavan (1989).

\subsection{Computational method}

The governing equations were discretized by a control-volume-based finite-difference method and solved by a line-by-line iterative procedure. In this connection, the momentum and energy equations were integrated over each control volume of the solution domain. Temperatures were evaluated at the centre of main control volumes, while a staggered grid was employed for velocity components. The continuity 
equation was integrated on the main control volumes to yield a pressure-correction equation.

Before integrating the differential equations, the convection and diffusion terms were combined to form a total flux term. A power-law scheme was used to interpolate total fluxes. The interface diffusion coefficients were obtained from the harmonic mean formula. The source terms were linearized and the convective boundary conditions were supplied as additional source terms. Care was exercised to avoid negative-slope linearization of the source terms, which could otherwise result in a diverged solution. Due to nonlinearity of the differential equations, underrelaxation had to be applied to the velocity components and the pressure. The underrelaxation values 0.5 and 0.8 , respectively for velocities and pressure, proved to be quite satisfactory. More details of the discretization and computational method are well documented by Patankar (1980).

Before the onset of computational runs, a comprehensive grid study was performed on the problem. The total number of grids were $1160,2350,3900,4290$, and 7968, while the various parameters were kept constant at $\mathrm{Ra}=10,000, \operatorname{Pr}=0 \cdot 7, \mathrm{Nu}_{\infty}=20$, $S=0.04, K=2800, R_{0} / R_{i}=2$ and $H=1$. The effect of grid size on $U, V$, and $T$ at the centre of the cavity indicated that these parameters changed with respect to the values for the finest grid (i.e., the 7968-point mesh) by $(5.32 \%, 1.78 \%, 0.61 \%, 0.61 \%)$, $(1.07 \%, 0.61 \%, 0.36 \%, 0.36 \%)$, and $(0.19 \%, 0.12 \%, 0.06 \%, 0.07 \%)$, respectively. These percentages indicated that a total of 3900 grid points would be sufficient to perform the present computations.

In the iterative procedure, the value of mass source in control volumes served as a convergence criteria. The iterations were continued until the maximum value of mass source did not exceed $10^{-7}$. With this criteria, the number of iterations ranged from 600 to 1200 . All computations were performed in double precision on a VAX 4000/200 computer. The CPU time ranged from 1 to 2 hours, with the 2-hour runs corresponding to the high Rayleigh numbers.

\section{Comparison with bench mark solution}

The precision of the present numerical technique and the computer code was evaluated by comparison with a bench mark solution. Apparently, no such solution is available for annular cavities. Therefore, the comparison is made with the rectangular cavity. It should be noted, however, that the rectangular cavity may be considered as a special case of the annular geometry where the radius ratio is equal to one. In fact, this comparison could also serve as a test of performance for the present code in such an extreme limiting case.

To facilitate the comparison with the bench mark solution of De Vahl Davis (1983), the radii of the cavity were increased to allow the radial inter-wall distance between the vertical walls of the cavity to reach $2.4 \%$ of the outer radius. This also increased the extent of the solution domain and the computation required more grid points. In addition, the top and bottom walls of the cavity were insulated, and the values of $\mathrm{Nu}_{\infty}$ and $K$ were increased respectively to $2 \times 10^{8}$ and $2.8 \times 10^{8}$ to ensure a uniform temperature on the vertical walls of the enclosure.

In this comparison, the computed quantities are the maximum vertical velocity on the horizontal mid-plane of the cavity, the maximum horizontal velocity on the vertical mid-plane of the cavity, the respective locations of these velocities, and the 
Nusselt number. The numerical results indicated a maximum difference of $2.0 \%$ in velocities and $1.7 \%$ in Nusselt number. This level of agreement between the present work and the bench mark solution under such an extreme limiting case is supportive of the present computational technique. Additional comparison with literature, including a comparison with one of the previous experimental results of the authors (Molki \& Shahsavan 1989) has been presented by Molki \& Faghri (1994).

Table 1. Values of parameters for figures $2-6$.

\begin{tabular}{|c|c|c|c|c|c|}
\hline Figure & $2 a$ & $2 b$ & $2 c$ & $2 d$ & \\
\hline \multirow[t]{9}{*}{$\begin{array}{l}\operatorname{Pr} \\
\mathrm{Ra} \\
n_{f} \\
L_{f} \\
T_{f} \\
S_{f}\end{array}$} & $\begin{array}{l}0.7 \\
1000 \\
8 \\
0.25 \\
0.02 \\
0.093\end{array}$ & $\begin{array}{l}0.7 \\
1000,000 \\
8 \\
0.25 \\
0.02 \\
0.093\end{array}$ & $\begin{array}{l}1000 \\
1000 \\
8 \\
0 \cdot 25 \\
0 \cdot 02 \\
0.093\end{array}$ & $\begin{array}{l}1000 \\
1000,000 \\
8 \\
0 \cdot 25 \\
0 \cdot 02 \\
0.093\end{array}$ & \\
\hline & $3 a$ & $3 b$ & $3 c$ & $3 d$ & $3 e$ \\
\hline & $\begin{array}{l}0.7 \\
100,000 \\
8 \\
0.25 \\
0.02 \\
0.093\end{array}$ & $\begin{array}{l}0.7 \\
100,000 \\
8 \\
0.125 \\
0.02 \\
0.093\end{array}$ & $\begin{array}{l}0.7 \\
100,000 \\
8 \\
0.063 \\
0.02 \\
0.093\end{array}$ & $\begin{array}{l}0.7 \\
100,000 \\
8 \\
0.031 \\
0.02 \\
0.093\end{array}$ & $\begin{array}{l}0.7 \\
100,000 \\
8 \\
0.016 \\
0.02 \\
0.093\end{array}$ \\
\hline & $4 a$ & $4 b$ & $4 c$ & $4 d$ & \\
\hline & $\begin{array}{l}0.7 \\
100,000 \\
12 \\
0.25 \\
0.02 \\
0.0585\end{array}$ & $\begin{array}{l}0.7 \\
100,000 \\
6 \\
0.25 \\
0.02 \\
0.1257\end{array}$ & $\begin{array}{l}0.7 \\
100,000 \\
4 \\
0.25 \\
0.02 \\
0.184\end{array}$ & $\begin{array}{l}0.7 \\
100,000 \\
2 \\
0.25 \\
0.02 \\
0.320\end{array}$ & \\
\hline & $5 a$ & $5 b$ & $5 c$ & $5 d$ & \\
\hline & $\begin{array}{l}0.7 \\
100,000 \\
8 \\
0.5 \\
0.009 \\
0.1031\end{array}$ & $\begin{array}{l}0.7 \\
100,000 \\
8 \\
0.25 \\
0.02 \\
0.0933\end{array}$ & $\begin{array}{l}0.7 \\
100,000 \\
8 \\
0.125 \\
0.042 \\
0.0735\end{array}$ & $\begin{array}{l}0.7 \\
100,000 \\
8 \\
0.063 \\
0.087 \\
0.0336\end{array}$ & \\
\hline & $6 a$ & $6 b$ & $6 c$ & $6 d$ & \\
\hline & $\begin{array}{l}0.7 \\
100,000 \\
16 \\
0.25 \\
0.01 \\
0.049\end{array}$ & $\begin{array}{l}0.7 \\
100,000 \\
8 \\
0.25 \\
0.02 \\
0.093\end{array}$ & $\begin{array}{l}0.7 \\
100,000 \\
4 \\
0.25 \\
0.04 \\
0.168\end{array}$ & $\begin{array}{l}0.7 \\
100,000 \\
2 \\
0.25 \\
0.08 \\
0.280\end{array}$ & \\
\hline
\end{tabular}




\section{Results and discussion}

Attention is now turned to the examination of the results. The results are grouped into two parts. Part one deals with the flow field, while part two considers the temperature. The principal parameters of each case are shown in tables 1 and 2.

Table 2. Values of parameters for figures $7-11$.

\begin{tabular}{|c|c|c|c|c|c|}
\hline Figure & $7 a$ & $7 b$ & & & \\
\hline $\begin{array}{l}\mathrm{Pr} \\
\operatorname{Ra} \\
n_{f} \\
L_{f} \\
T_{f} \\
S_{f}\end{array}$ & $\begin{array}{l}0.7 \\
1000 \\
8 \\
0 \cdot 25 \\
0.02 \\
0.093\end{array}$ & $\begin{array}{l}1000 \\
1000,000 \\
8 \\
0 \cdot 25 \\
0 \cdot 02 \\
0.093\end{array}$ & & & \\
\hline & $8 a$ & $8 b$ & $8 \mathrm{c}$ & $8 d$ & $8 e$ \\
\hline & $\begin{array}{l}0.7 \\
100,000 \\
8 \\
0 \cdot 25 \\
0.02 \\
0.093\end{array}$ & $\begin{array}{l}0.7 \\
100,000 \\
8 \\
0.125 \\
0.02 \\
0.093\end{array}$ & $\begin{array}{l}0.7 \\
100,000 \\
8 \\
0.063 \\
0.02 \\
0.093\end{array}$ & $\begin{array}{l}0.7 \\
100,000 \\
8 \\
0.031 \\
0.02 \\
0.093\end{array}$ & $\begin{array}{l}0.7 \\
100,000 \\
8 \\
0.016 \\
0-02 \\
0.093\end{array}$ \\
\hline & $9 a$ & $9 b$ & & & \\
\hline & $\begin{array}{l}0.7 \\
100,000 \\
12 \\
0.25 \\
0.02 \\
0.0585\end{array}$ & $\begin{array}{l}0.7 \\
100,000 \\
2 \\
0.25 \\
0.02 \\
0.32\end{array}$ & & & \\
\hline & $10 \mathrm{a}$ & $10 b$ & $10 c$ & $10 \mathrm{~d}$ & \\
\hline & $\begin{array}{l}0.7 \\
100,000 \\
8 \\
0 \cdot 5 \\
0.009 \\
0.103\end{array}$ & $\begin{array}{l}0.7 \\
100,000 \\
8 \\
0.25 \\
0.02 \\
0.093\end{array}$ & $\begin{array}{l}0 \cdot 7 \\
100,000 \\
8 \\
0 \cdot 125 \\
0.042 \\
0.0735\end{array}$ & $\begin{array}{l}0.7 \\
100,000 \\
8 \\
0.063 \\
0.087 \\
0.0336\end{array}$ & \\
\hline & $11 \mathrm{a}$ & $11 b$ & $11 \mathrm{c}$ & $11 d$ & \\
\hline & $\begin{array}{l}0.7 \\
100,000 \\
16 \\
0.25 \\
0.01 \\
0.0494\end{array}$ & $\begin{array}{l}0.7 \\
100,000 \\
8 \\
0.25 \\
0.02 \\
0.093\end{array}$ & $\begin{array}{l}0.7 \\
100,000 \\
4 \\
0.25 \\
0.04 \\
0.168\end{array}$ & $\begin{array}{l}0.7 \\
100,000 \\
2 \\
0.25 \\
0.08 \\
0.280\end{array}$ & \\
\hline
\end{tabular}




\subsection{The flow field}

The interaction between the main buoyancy-driven flow and the array of annular cavities is demonstrated by the streamlines of figure 2 . In this figure, the right boundaries of the inter-fin cavities are exposed to the large-scale recirculation in the main enclosure (see figure 1), while the top, bottom, and left sides are bounded by the solid walls. The wall and the fins are warmer than the neighbouring fluid and generate a clockwise rotation in the main buoyancy-driven flow (figure 1).

It is seen from table 1 that figures $2 a \& b$ and figures $2 c \& d$ are prepared for the same Prandtl number ( $\mathrm{Pr}$ ) but different Rayleigh numbers $(\mathrm{Ra})$. Examination of these streamlines indicates that at low Rayleigh numbers (figure $2 \mathrm{a} \& \mathrm{c}$ ), the cavities are washed by twin recirculating flows which rotate in opposite directions. The recirculating bubbles situated to the right have a counter clockwise rotation, while those located to the left have a clockwise rotation. The top and bottom cavities, however, are somewhat different, since their exposure to the main large-scale recirculation is different. In these specific locations, only one single bubble is observed, which is larger and more energetic.

At higher values of $\mathrm{Ra}$ (figures $2 \mathrm{~b} \& \mathrm{~d}$ ), the main flow enters the cavities of the array where it partially disturbs or completely removes the twin recirculating bubbles. The streamlines in these figures indicate that the extent of this interaction increases with $\mathrm{Pr}$, and the main recirculating flow moves into the cavities. It is noteworthy
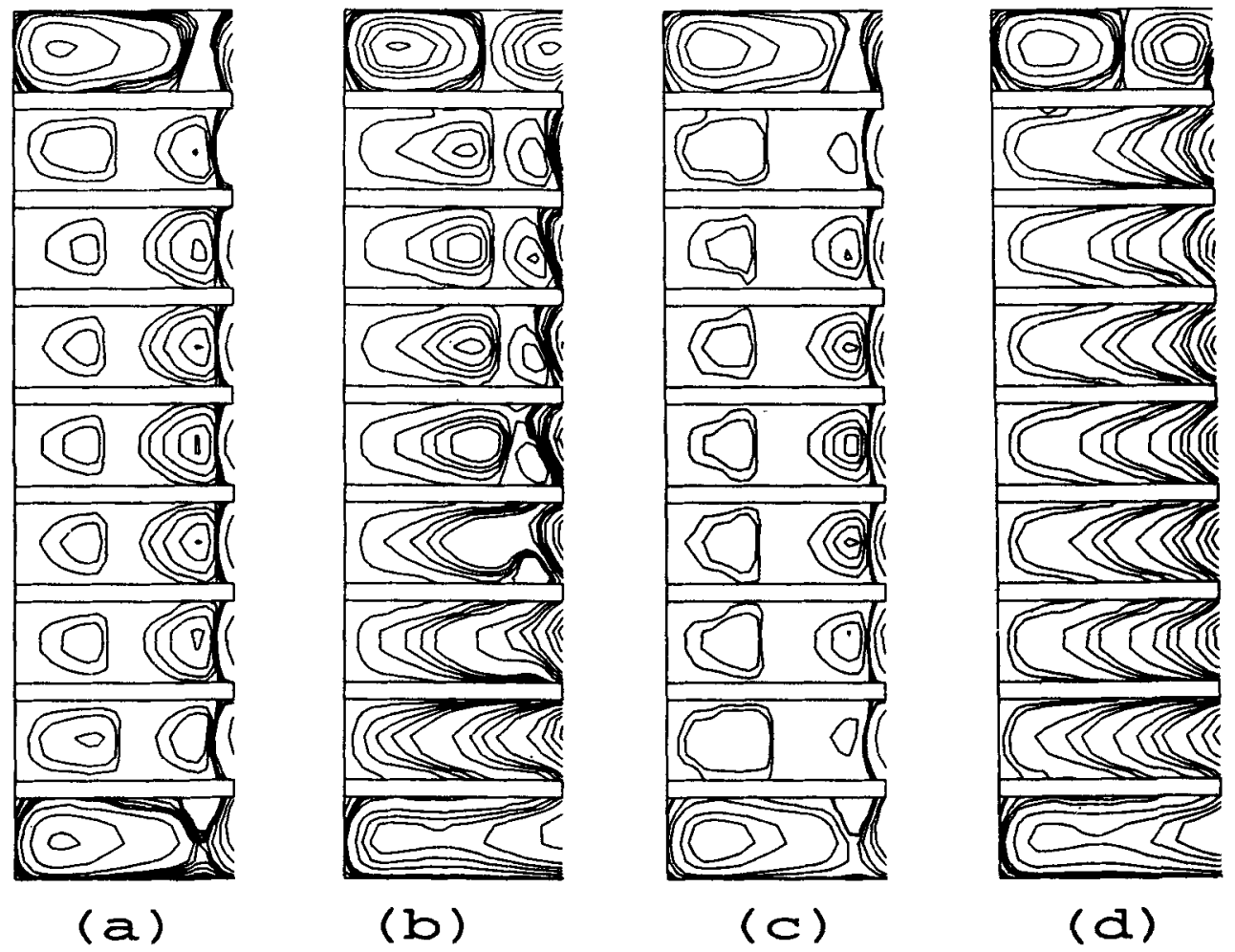

Figure 2. Effect of Pr and Ra on the flow field in the array of cavities; twin recirculating bubbles are seen inside most of the cavities. 


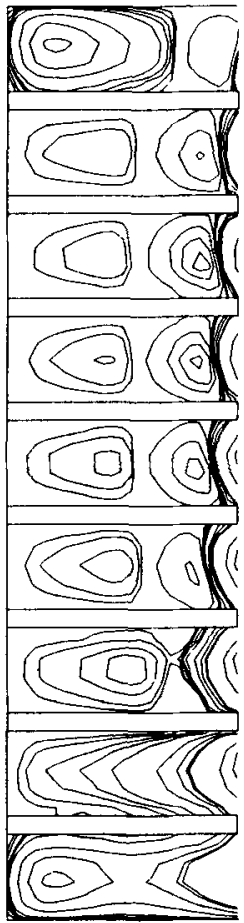

(a)

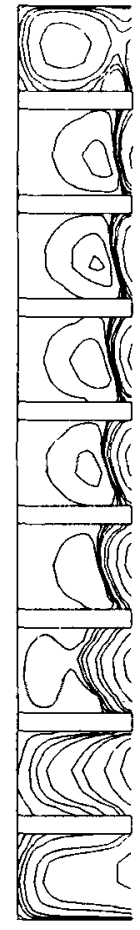

(b)
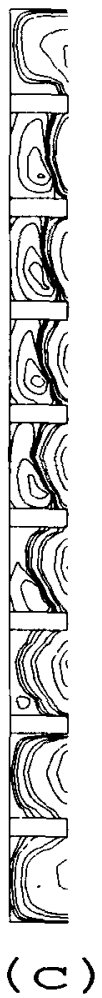
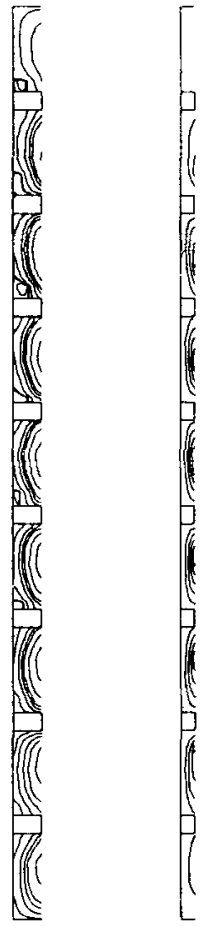

(d) (e)

Figure 3. Effect of fin length on the flow field. The recirculating bubbles become smaller and eventually disappear as the cavities become more shallow.

that these flow features are often encountered in finned walls, and they can have a significant effect on heat transfer.

Effect of fin length or depth of cavities on the flow field is shown in figure 3, and the relevant parameters are given in table 1 . It is seen from the figure that the twin recirculating bubbles are greatly affected by the fin length. The bubble adjacent to the wall disappears as the fin length is reduced and the cavities become shallow (figure 3a). Further reduction of the fin length brings the main recirculating flow closer to the cavities and there is more interaction with the cavity fluid. It is clear from figures $3 \mathrm{~d}-\mathrm{e}$ that for shallow cavities, the recirculating bubbles disappear and the main flow enters the inter-fin spacings with no difficulty.

In figure 4, the streamlines are presented for different number of fins. The cavities become more slender as the number of fins is increased. In this case, the next-to-the-wall recirculating bubbles tend to collapse and split into two parts (figure $4 a)$. On the other hand, the extent of flow interaction increases as the number of fins is decreased and the main flow moves into the interfin spacings (figure $4 \mathrm{~d}$ ).

The finned walls are often optimized with respect to their thickness and number. In this regard, the fin length can be either increased with constant thickness, or it can be increased under the constraint that the fin mass remains constant. With this constraint, a longer fin has to be thinner and a shorter fin must be thicker.

The streamlines of figures 5-6 are obtained with the restriction that the total fin 


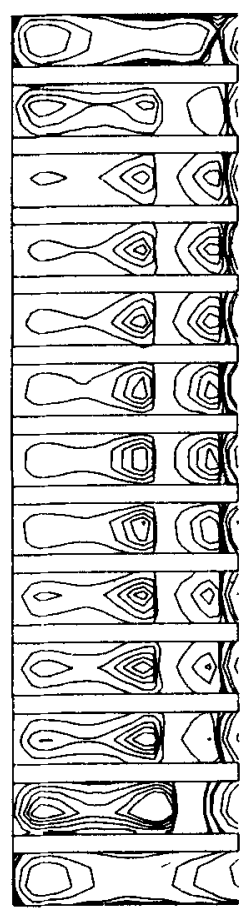

(a)

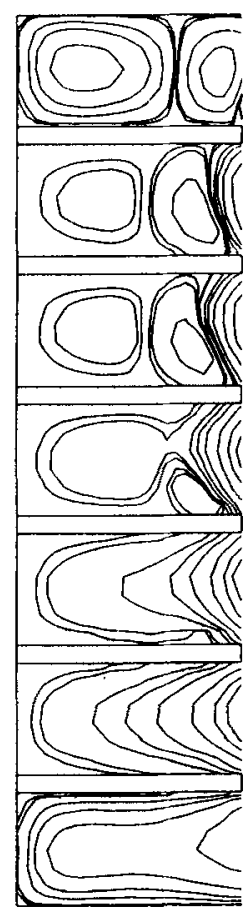

(b)

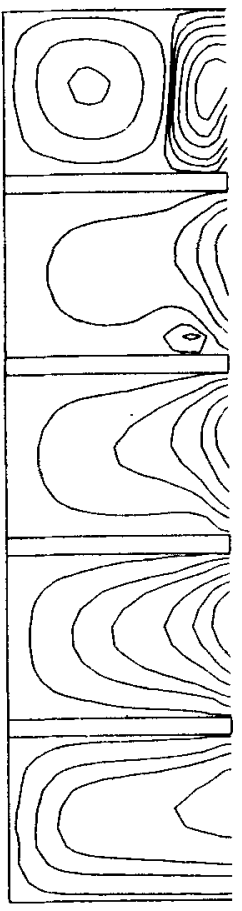

(C)

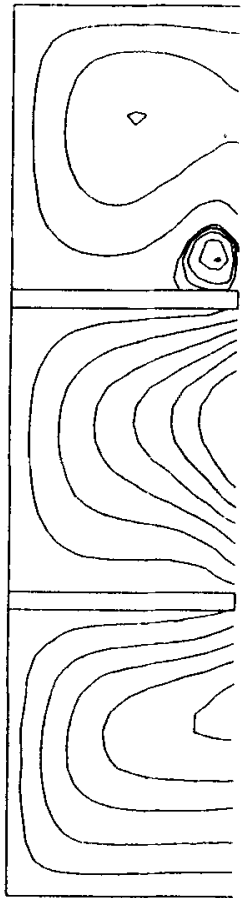

(d)

Figure 4. Effect of number of fins on the flow field. Larger number of fins tends to stretch the next-to-the-wall recirculating bubbles ad split them into two parts.

mass remains constant. In figure 5 , the fin length is reduced under the constant-mass constraint and the number of fins is constant, while in figure 6, the fin length is held constant and the number of fins is reduced. It is clear from figure 5 that the number and extent of the recirculating bubbles are reduced with the fin thickness. However, as evidenced from figure 6 , the main flow moves into the cavities as the number of fins is decreased.

\subsection{The temperature field}

Representative isotherms for the array of cavities are presented in figures 7-11, with the respective parameters given in table 2 . In figure 7, the effect of $\operatorname{Pr}$ and $\mathrm{Ra}$ on temperature distribution indicates that there is a larger temperature variation in the top and bottom cavities of the array, while the temperature gradient in the remaining cavities is relatively small. This observation is consistent with the fact that the flow in the top and bottom cavities is more dynamic. As is evident from the earlier streamlines, the main flow often penetrates into these cavities with less difficulty, thus permitting better exchange of thermal energy.

Figure 8 shows the effect of fin length on the temperature field. According to table 2, the figure is prepared for a ixed $\mathrm{Pr}$ and $\mathrm{Ra}$, with the fin thickness being constant. Again, it is seen that the temperature variation in the cavities situated at the far ends 

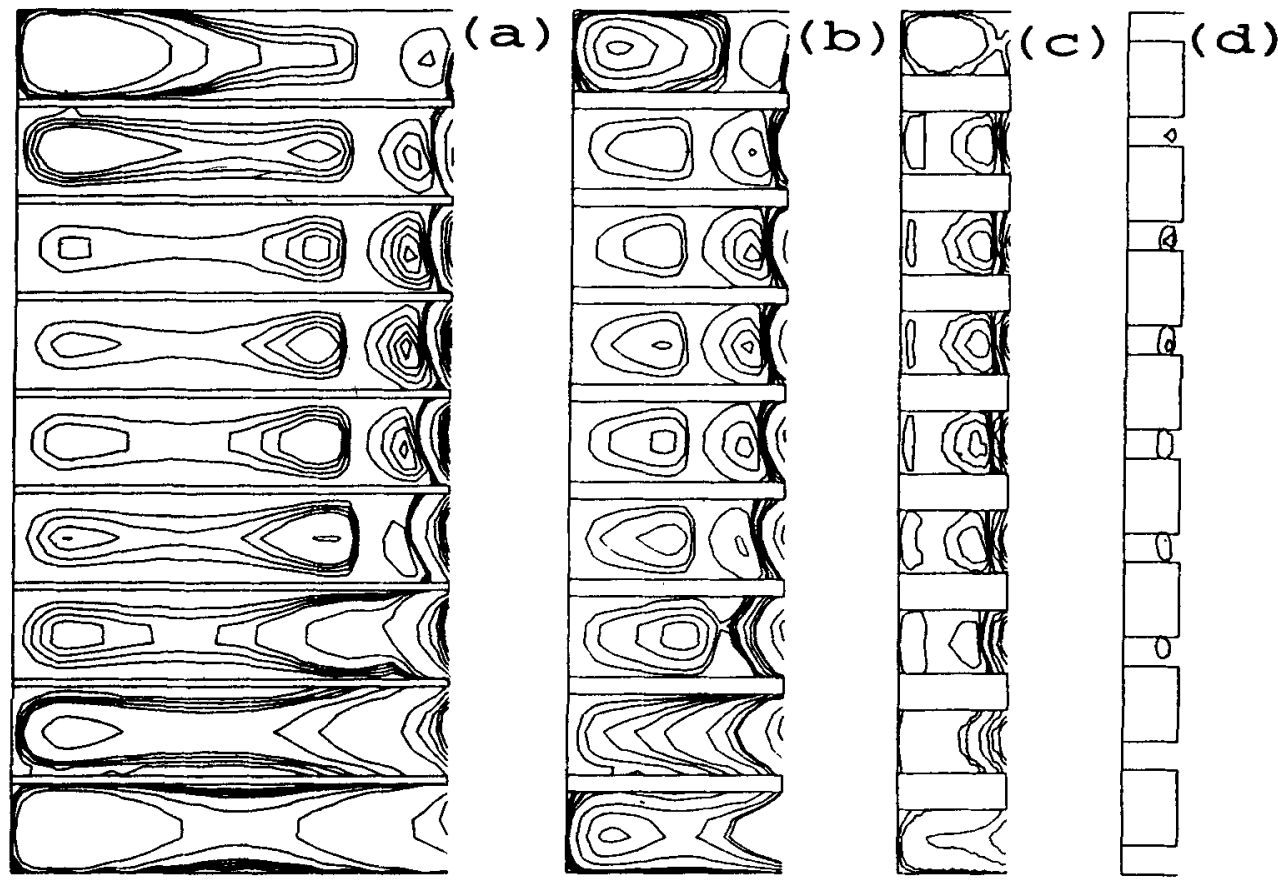

Figure 5. Effect of fin length under constant-mass restriction; the number and extent of the bubbles are reduced with the thickness.
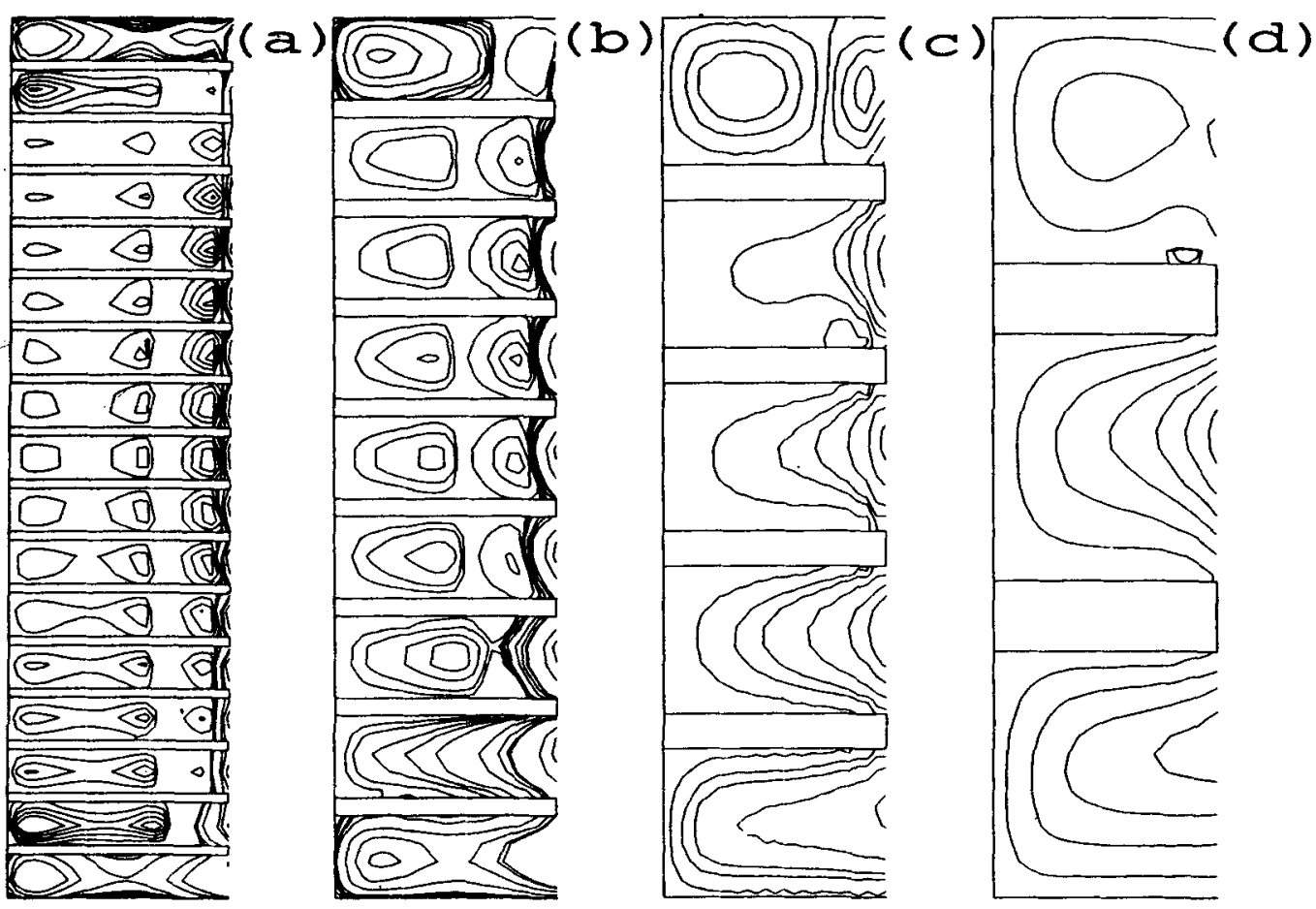

Figure 6. Effect of number of fins under constant-mass restriction; the main flow enters the cavities as the number of fins is decreased. 

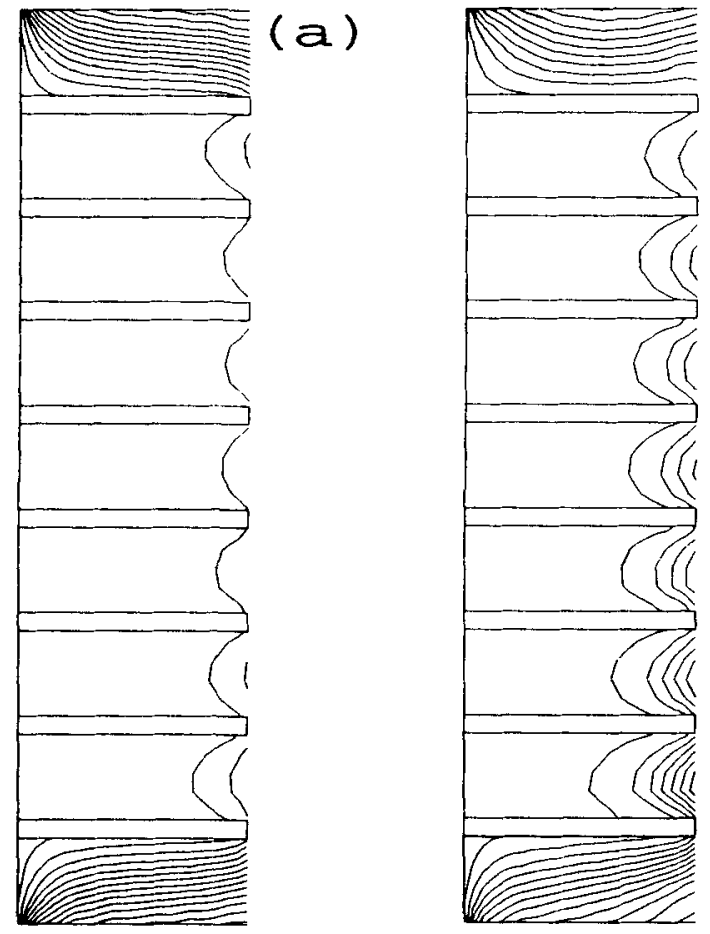

(b)

Figure 7. Effect of $\mathrm{Pr}$ and $\mathrm{Ra}$ on isotherms; larger temperature gradients are seen near the fin tips and also in the top and bottom cavities.

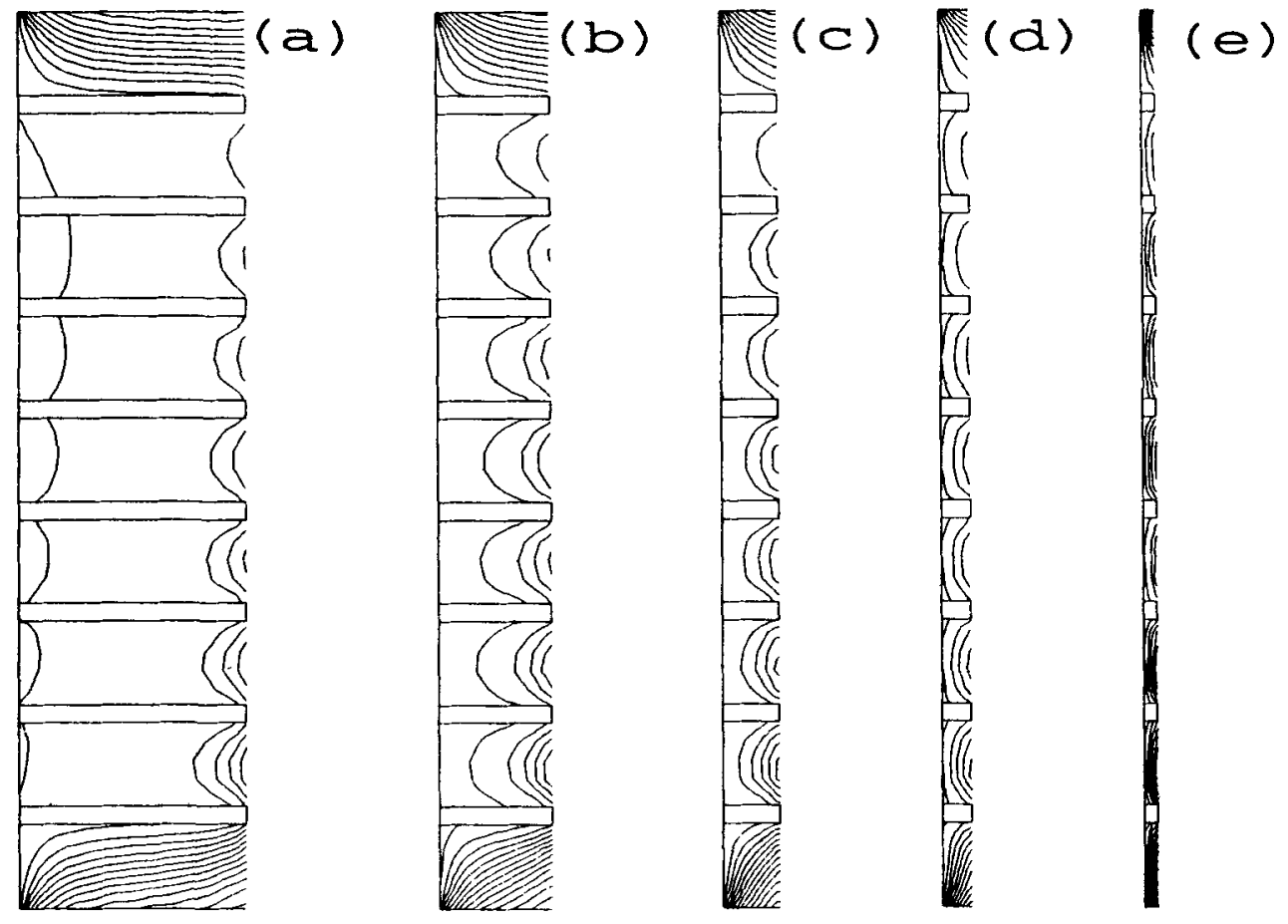

Figure 8. Effect of fin length on isotherms; more temperature variation is observed as the fin length is reduced. 

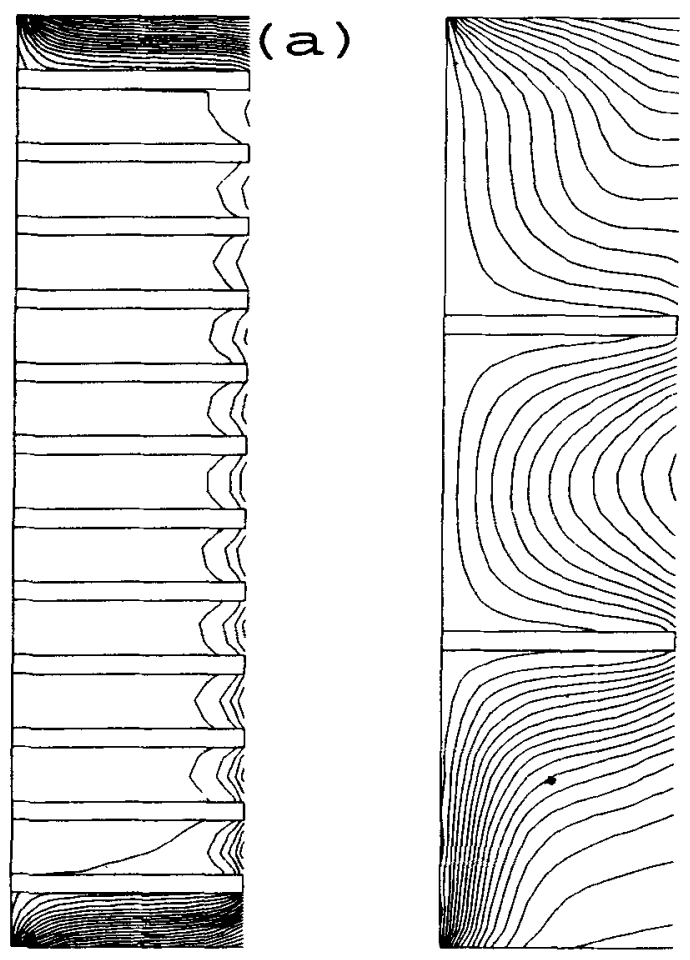

(b)

Figure 9. Effect of number of fins on isotherms; for larger number of fins, a nearly isothermal zone is seen in the finned area.
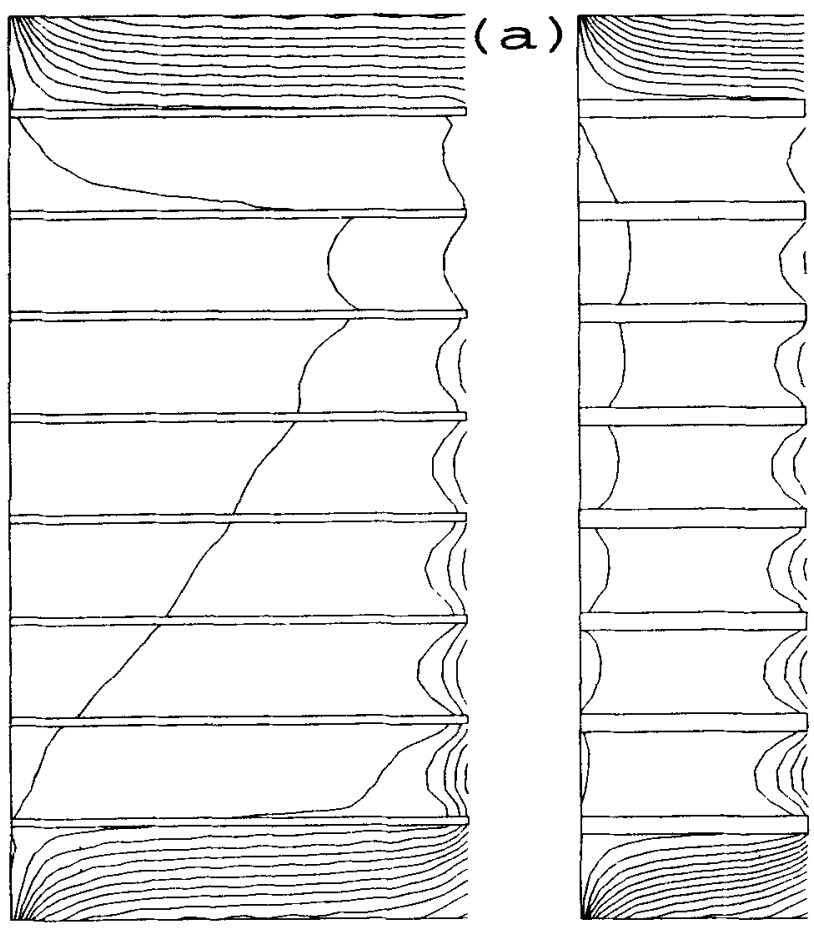

(b)

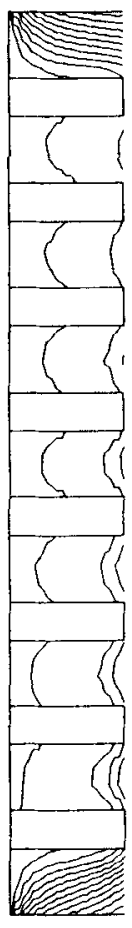

(c)

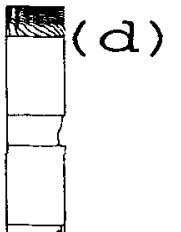

Figure 10. Effect of fin length on isotherms under constant-mass restriction. 


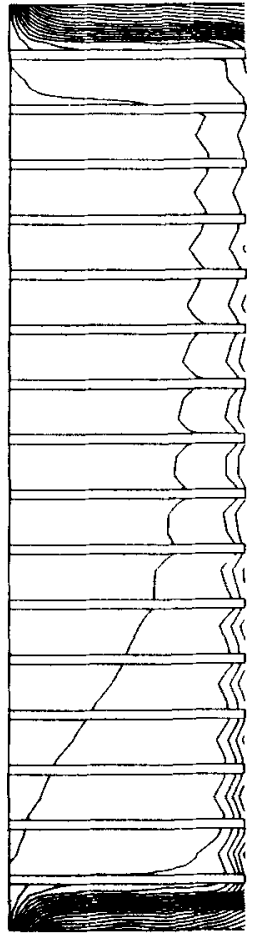

(a)

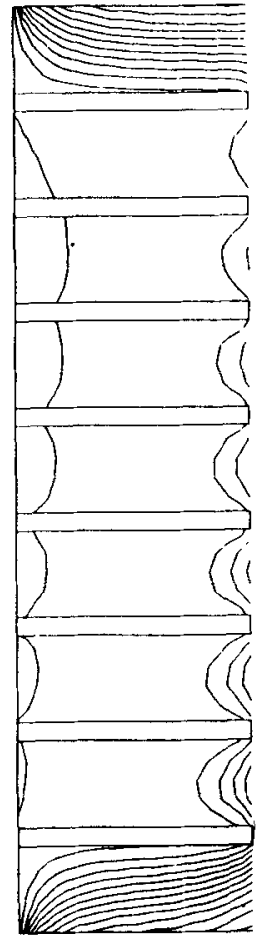

(b)

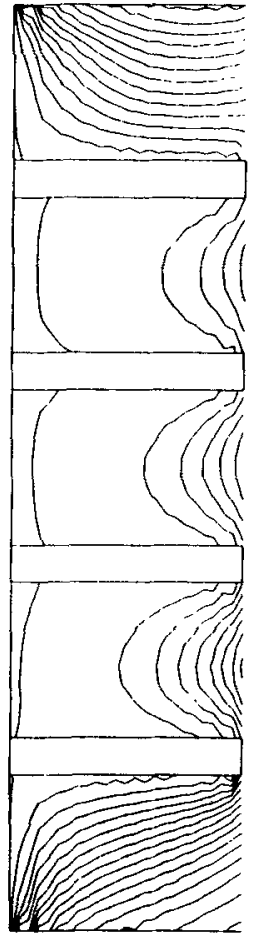

(c)

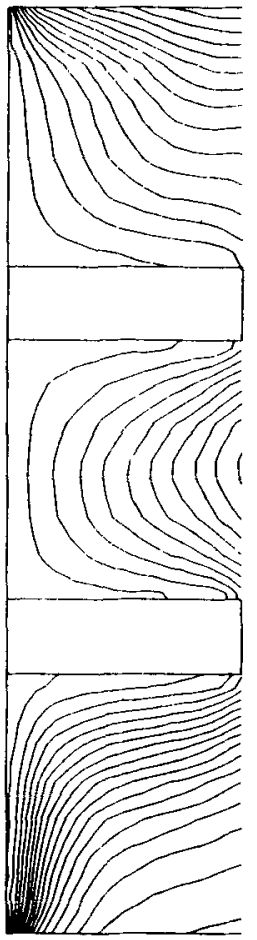

(d)

Figure 11. Effect of number of fins on isotherms under constant-mass restriction.

of the array is much larger. As the fin length is reduced, the extent of the nearly uniform temperature zone created by the presence of the fins is also reduced and there is a closer thermal communication between the finned wall and the main buoyancy-driven flow.

Figure 9 indicates the effect of number of fins on the cavity isotherms. With more fins, the recirculating bubbles are present in the cavities and the thermal communication between the finned wall and the main flow is through the multiple bubbles. As the number of fins is diminished, the size of cavities in vertical direction is increased and the main fluid comes into a close contact with the finned wall. It is seen in this figure that the temperature variation increases with the fin spacing.

At a given temperature difference, there are two parameters which determine the magnitude of heat transfer. These are the heat transfer coefficient and the surface area. As the fin length or the number of fins is reduced, the area decreases and this tends to decrease heat transfer from the wall. On the other hand, the presence of recirculation zones in the inter-fin spacings has an enhancing effect on heat transfer coefficient, so that the overall effect is determined by the combined effect of these parameters. In a previous study, the authors (Molki \& Faghri 1994) have indicated that for the case of constant heat generation within the finned wall, the wall temperature decreases as the number of fins or their length is increased.

Isotherms for fin arrangements of constant mass are shown in figures 10-11. Again, the temperature variation in the cavities situated at the far ends of the array is 
relatively large. The figures also indicate that the effect of fin spacing (or number of fins) on isotherms is stronger than that caused by the fin length.

\section{Conclusion}

The paper described a numerical investigation of the effect of a buoyancy-driven flow on an array of annular cavities. The buoyant flow is generated by temperature gradient in an annular enclosure where the resulting flow interacts with an array of smaller cavities inside the enclosure. The study is focused on the qualitive description of the flow and temperature fields.

At low $\mathrm{Ra}$ numbers, a twin recirculating bubble is observed in the array of cavities which rotate in opposite directions. As $\mathrm{Ra}$ increases, flow patterns undergo a transition so that at higher $\mathrm{Ra}$, the main flow is able to enter the cavities and remove the recirculation bubbles. These observations are more pronounced at higher $\mathrm{Pr}$ number.

Another noteworthy parameter which affects the flow patterns is the depth of cavities or fin length. As the cavity depth is reduced, the recirculation bubbles adjacent to the bottom wall of cavities disappear. Further decrease of depth would remove all recirculation from within the cavities and would bring the main flow into a closer thermal communication with the finned wall.

Flow patterns are also affected by the vertical dimension of cavities. For more slender and deeper cavities, the recirculating bubbles that are closer to the finned wall collapse and split into two bubbles.

Examination of the temperature field indicates that there is a large temperature variation at the top and bottom cavities of the array, while the temperature gradient in the remaining cavities is relatively small. An overall review of the isotherms shows that the presence of the cavities creates a nearly uniform high-temperature zone adjacent to the finned wall. However, as the fin length is reduced and the cavities become more shallow, this uniform-temperature zone is shrunk and the main buoyancy-driven flow maintains a closer thermal communication with the finned wall.

The first author gratefully acknowledges that the funding for this project was provided by the Esfahan University of Technology.

\section{List of symbols}

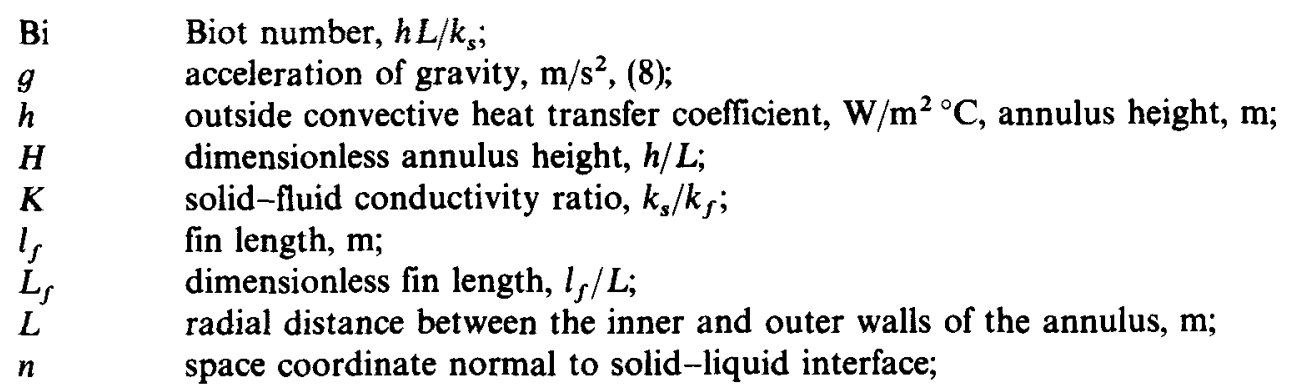


$n_{f} \quad$ number of fins;

$N \quad$ dimensionless $n, \mathrm{n} / L$;

$\mathrm{Nu}_{x} \quad$ Nusselt number outside the annulus, $h L / k_{f},(12)$;

$p \quad$ pressure, $\mathrm{Pa},(8)$;

$P \quad$ dimensionless pressure, (8);

Pr Prandtl number, $v / \alpha$;

$\mathrm{R}$ dimensionless radial coordinate, $r / L,(6)$;

$r_{i} \quad$ radius of the inner cylinder, $\mathrm{m}$;

$r_{o} \quad$ radius of the outer cylinder, $m$;

$R_{i} \quad$ dimensionless radius of the inner cylinder, $r_{i} / L$;

$R_{o} \quad$ dimensionless radius of the outer cylinder, $r_{o} / L$;

$\mathrm{Ra} \quad$ Rayleigh number, (9);

heat generation within the inner cylinder, $\mathrm{W} / \mathrm{m}^{3},(9)$;

dimensionless $s,(9)$;

$t_{f} \quad$ fin thickness, $\mathrm{m}$;

$t \quad$ temperature, ${ }^{\circ} \mathrm{C},(7)$;

$t_{\infty} \quad$ temperature of the surroundings, ${ }^{\circ} \mathrm{C},(7)$;

$T_{f} \quad$ dimensionless fin thickness, $t_{f} / L$;

$T_{r} \quad$ reference temperature, ${ }^{\circ} \mathrm{C},(8)$;

$T \quad$ dimensionless temperature, $t / t_{\infty},(7)$;

$U \quad$ velocity component in $x$ direction, $u /(v / L),(7)$;

$V \quad$ velocity component in $r$ direction, $v /(v / L),(7)$;

$X \quad$ axial coordinate, $x / L,(6)$;

$\beta \quad$ volumetric coefficient of thermal expansion, $1 / K,(8)$;

$v \quad$ kinematic viscosity of fluid, $\mathrm{m}^{2} / \mathrm{s}$;

$\rho \quad$ fluid density, $\mathrm{kg} / \mathrm{m}^{3}$;

$\rho_{r} \quad$ reference density, $\mathrm{kg} / \mathrm{m}^{3}$.

\section{Subscripts}

$\begin{array}{ll}f & \text { fluid, fin; } \\ i & \text { inner cylinder; } \\ o & \text { outer cylinder; } \\ s & \text { solid; } \\ \infty & \text { surroundings. }\end{array}$

\section{References}

Benjamin A S, Denny V E 1979 On the convergence of numerical solutions for two-dimensional flows in a cavity at large Re. J. Comput. Phys. 33: 340-358

Bhushan R, Keyhani M, Christenen R N, Kulacki F A 1983 Correlations for convective heat transfer in vertical annular gas layers with constant heat flux on the inner wall. ASME J. Heat Tranfer 105: 910-912

Bozeman J D, Dalton C 1973 Numerical study of viscous flow in a cavity. J. Comput. Phys. 12: $348-363$

Catton I 1978 Natural convection in enclosures. Proc. 6th Int. Heat Transfer Conf. Toronto, Canada, 6: 13-31

Collier J G, Boyce B E, deForge Dedman A S, Khanna R 1970 Natural convection through narrow vertical unheated annuli at high gas pressures. Proc. 4th Int. Heat Transfer Conference, Paris-Versailles, vol. 4, paper NC 2.6 
De Vahl Davis G 1983 Natural convection of air in a square cavity: a bench mark numerical solution. Int. J. Numer. Methods Fluids 3: 249-264

De Vahl Davis G, Thomas R W 1969 Natural convection between concentric vertical cylinders, high-speed computing in fluid dynamics. Phys. Fluids Suppl. II pp. 198-207

Farouk B, Ball K S, Dixit V C 1990 Aspect and radius ratio effects on natural convection in a vertical annulus. Proc. 9th Int. Heat Transfer Conference, Jerusalem, Israel, vol. 2 pp. $585-590$

Ghia U, Ghia K N, Shin C T 1982 High-Re solutions for incompressible flow using the Navier-Stokes equations and a multigrid method. J. Comput. Phys. 48: 387-411

Hoogendoorn C J 1986 Natural convection in enclosures. Proc. 8th Int. Heat Transfer Conf. San Francisco, CA, USA 1: 111-120

Iwatsu R, Hyun J M, Kuwahara K 1990 Analyses of three-dimensional flow calculations in a driven cavity. Fluid Dyn. Res. 6: 91-102

Iwatsu R, Hyun J M, Kuwahara K 1992 Numerical simulation of flows driven by a torsionally oscillating lid in a square cavity. J. Fluids Eng. 114: 143-151

Iwatsu R, Ishii K, Kawamura T, Kuwahara K, Hyun J M 1989 Numerical simulation of three-dimensional flow structure in a driven-cavity. Fluid Dyn. Res. 5: 173-189

Keyhani M, Kulacki F A, Christensen R N 1983 Free convection in a vertical annulus with constant heat flux on the inner wall. ASME J. Heat Transfer 105: 454-459

Lin D S, Nansteel M W 1987 Natural convection in a vertical annulus containing water near the density maximum. ASME J. Heat Transfer 109: 899-905

Molki M, Faghri M 1994 Conjugate natural convection heat transfer in a vertical annulus with internal circumferential fins. Numer. Heat Transfer A25: 457-476

Molki M, Shahsavan M 1989 Enhancement of natural convection heat transfer in annular enclosures J. Eng. 2: 45-53

Nagendra H R, Tirunarayanan M A, Ramachandran A 1970 Free convection heat transfer in vertical annuli. Chem. Eng. Sci. 25: 605-610

Ostrach S 1982 Natural convection heat transfer in cavities and cells Proc. 7th Int. Heat Transfer Conf. 1: 365-379

Ostrach S 1988 Natural convection in enclosures. ASME J. Heat Transfer 110: 1175-1190

Ozawa $S 1975$ Numerical studies of steady flow in a two-dimensional square cavity at high Reynolds numbers. J. Phys. Soc. Jpn. 38: 889-895

Patankar S V 1980 Numerical heat transfer and fluid flow (New York: McGraw Hill)

Prasad V, Kulacki F A 1985 Free convective heat transfer in a liquid-filled vertical annulus. ASME J. Heat Transfer 107: 596-602

Schreiber R, Keller H B 1983 Driven cavity flow by efficient numerical technique. J. Comput. Phys. 49: 310-333

Sheriff $\mathrm{N} 1966$ Experimental investigation of natural convection in single and multiple vertical annuli with high pressure carbon dioxide. Proc. 3rd Int. Heat Transfer Conf. vol. 2: 132-138

Thomas R W, De Vahl Davis G 1970 Natural convection in annular and rectangular cavities, a numerical study. Proc. 4th Int. Heat Transfer Conf. vol 4, paper NC 2.4

Tuann S Y, Olson M D 1978 Review of computing methods for recirculating flows. J. Comput. Phys. 29: 1-19

Vijayan P K, Saha D, Venkat Raj V 1986 Studies on natural convection in vertical annuli heated from below. Proc. 8th Int. Heat Transfer Conf. San Fransisco, CA, 4: 1563-1568 